\title{
THE GENETICAL CONTROL OF SELF-INCOMPATIBILITY IN PAPAVER RHOEAS
}

\author{
M. J. LAWRENCE, M. AFZAL and J. KENRICK \\ Department of Genetics, University of Birmingham, Birmingham B/5 2TT
}

Received 2.vi.77

\begin{abstract}
Summary
In a previous paper evidence was presented which, it was argued, suggested that self-incompatibility in Papaver rhoeas was determined by a single, multiallelic locus and that control of the pollen phenotype was gametophytic. In the present paper further evidence is given which proves that control of the pollen is gametophytic and which all but excludes the possibility that more than one locus is involved. The implications of these results in respect of the hypothesis that one-locus systems have evolved from multi-locus systems of selfincompatibility are discussed.
\end{abstract}

\section{INTRODUCTION}

IN a preliminary investigation of the genetics of self-incompatibility in the Field Poppy Papaver rhoeas, Lawrence (1975) showed that the pattern of pollinations obtained by crossing plants within each of three families was consistent with the hypothesis that in this species control of the incompatibility reaction of the pollen is gametophytic. This conclusion rested on three separate pieces of evidence. Firstly, cytological observation of pollen-tube growth on the stigma showed that all compatible pollinations were of the half-compatible kind. Secondly, in all three families, individuals fell into one or other of two intra-incompatible, inter-compatible pollination classes. Thirdly, whenever a cross between two plants was made reciprocally the outcome obtained was always the same in that either both were incompatible or both were half-compatible.

Of these three pieces of evidence, the first is, of course, the most persuasive, since half-compatible pollinations are encountered only when a proportion of the pollen is of one compatible phenotype, the remaining portion being of a second incompatible phenotype; that is, control of the pollen phenotype is gametophytic. The other two pieces of evidence, on the other hand, are no more than consistent with the hypothesis that control of the pollen phenotype is gametophytic. Thus families whose individuals fall into two pollination classes and in which crosses can be made reciprocally are expected, given certain assumptions, in species whose pollen reaction is under sporophytic control. Taken by itself, therefore, this genetical evidence is a good deal less than conclusive. One of the two chief purposes of the present paper is to present some further genetical evidence concerning pollination relationships between parents and offspring which puts this matter beyond doubt.

The second purpose of the present report is to deal with the question of the number of loci involved in the control of self-incompatibility in 
P. rhoeas. Now in the previous paper it was argued that the data were consistent with the hypothesis that control was exercised by a single gene with multiple alleles. Thus, as mentioned earlier, the individuals of both of the families produced by conventional pollination fell into just two pollination classes. Furthermore, with the possible exception of two isolated cases in the Solanaceae (Pandey 1957, 1962), control in all dicotyledonous species with a homomorphic system of self-incompatibility has been found hitherto to depend on a single locus (Lewis, 1954; Arasu, 1968), multilocus systems being confined, apparently to the monocotyledonous grasses in which two, multi-allelic, loci are involved (Hayman, 1956; Lundqvist, 1956, 1961). In the light of this evidence, therefore, there seemed little to be gained by subjecting this conclusion to serious scrutiny.

This situation has now changed, however, for recently Lundqvist et al. (1973) and Østerbye (1975) have found that both Ranunculus acris (Ranunculaceae) and Beta vulgaris (Chenopodiaceae) have multilocus systems, the former species having at least three and the latter at least four loci. In both species control of the pollen reaction is apparently gametophytic and there is a multiple allelic series at each of the several loci. Furthermore, though $P$. rhoeas and $R$. acris belong, of course, to different families, both Takhtajan (1969) and Cronquist (1968) consider that the order to which the Papaveraceae belong, the Papaverales, has probably arisen as an evolutionary side-branch from the Ranunculales, the order in which the Ranunculaceae are placed. In the light of this new evidence, therefore, the question of the number of loci which determine self-incompatibility in $P$. rhoeas, and, indeed, in other members of the more primitive orders of dicotyledons, is clearly no longer a trivial one.

Now the data of the previous paper came from three families that had been obtained by inbreeding, two of them (families 1 and 2) had been produced by two generations of sib-mating and the third (family 3 ) by the enforced self-pollination of a non-inbred individual. This kind of material is not, unfortunately, very suitable for tests that are intended to distinguish between the alternative hypotheses of one versus multilocus control. Thus in species with a multilocus system of self-incompatibility, individuals which are homozygous with respect to one or more loci are expected and indeed are found; that is, homozygotes are a regular feature of such systems, the minimum requirement being that plants must differ at just one locus if they are to be compatible. Now if, by chance, two individuals are mated which are identically homozygous at all loci except one, their progeny will fall into either two or four pollination classes, depending on whether the parents have an allele in common at their heterozygous locus. Such an outcome, of course, exactly mimics the situation we expect to find in full-sib families of species with one-locus control. For this reason, Lundqvist (1975) has referred to this circumstance as a pseudo-one-locus system. Furthermore inbreeding is expected to increase the probability of homozygosity at incompatibility as well as other loci and hence to increase, also, the incidence of pseudo-one-locus pollination patterns. Thus the question of the number of loci that are involved in the control of self-incompatibility in $P$. rhoeas is, on the evidence so far available, far from settled.

In the present paper we accordingly present evidence from four noninbred families of full-sibs which goes a long way towards the resolution of this problem. 


\section{Materials AND methods}

The three families of plants with which we are concerned in respect of the genetical control of the pollen phenotype are all related to family (1) of the previous paper (Lawrence loc. cit.). The members of the first family $\left(1^{\prime}\right)$ were raised from seed taken from the same packet as was that used in the previous season to raise the plants of family (1). The former, therefore, is expected to contain plants which fall into the same two pollination classes, I and II, as those of the latter. The remaining two families, (1A) and (1B), were raised from seed produced by crossing plants of different pollination group in family 1 reciprocally. Thus family (1A) was produced by crossing plant No. 18 (I) as female, with plant No. 24 (II) as male. Similarly, family (1B) was produced by crossing plant No. 24 (II) as female, with plant No. 4 (I) as male (see p. 278 of previous paper for further details).

Four families of full-sibs, families $73,75,76$ and 80 , were used to investigate the question of the number of loci involved in the determination of self-incompatibility in the species. The eight parent individuals of these four families were raised from seed taken from a natural population found near Pillerton Priors in Warwickshire. Unlike family 1 and its relatives, therefore, this material had not been inbred.

The seed of each of these seven families was subjected to the customary sulphuric acid-low temperature treatment in order to break its dormancy before being sown in $60 \mathrm{~mm}$ "Jiffy" peat pots containing John Innes potting compost No. 1 in the glasshouse. The seed of the three inbred families was treated and sown in the spring of 1974 (10) plants being raised in family $\mathrm{l}^{\prime}$ and (30) plants in each of families $\mathrm{lA}$ and $\mathrm{lB}$. Later in the season, the plants of these families were transplanted to open ground when they had attained an appropriate size. The seed of the four non-inbred families was treated and sown at the end of July 1975, 20 plants being raised in each family. Later in the season, these plants were potted on into $170 \mathrm{~mm}$ clay pots which contained J.I.P. No. 1 compost that had received a dressing of the systemic fungicide "Benlate". The latter is an important part of the procedure because when poppies are grown under glass out of season they are otherwise very susceptible to attack by mildew. The plants were grown under 400-watt high-pressure mercury-fluorescent lamps set to provide a 16-hour day-length.

The incompatibility relationships of these plants were determined. cytologically by examining pollen-tube growth on the stigmas of emasculated flowers using a modification of Martin's (1959) fluoresence microscopy method. Stigmas were fixed 24 hours after pollination in Carnoy's fixative for 8-24 hours before being softened in a normal solution of sodium hydroxide at a temperature of $60^{\circ} \mathrm{C}$ for 5-10 minutes. After rinsing in tap-water, the softened stigmas were then transferred intact to a buffered solution of $0 \cdot 2$ per cent aniline blue where they remained until they were required. Squashes of single stigmatic rays that had been cut out of stigmas handled in this way were then examined under the microscope in order to ascertain the outcome of the pollination. We have encountered little difficulty in distinguishing between incompatible, half-compatible and fully compatible pollinations in this species when using this procedure provided that care is taken to choose stigmas for pollination that are fully mature. Further details concerning the difference between the appearance of incompatible 
and compatible pollen as seen under the microscope may be found in the previous paper.

The ease and speed with which pollinations can be examined with the aniline blue-fluorescence technique make it a highly efficient method for the classification of plants into two or more cross-compatible classes. For this reason we have been able to avoid the rather tedious chore of having to make all possible crosses between the members of a sibship in order to achieve a complete and unambiguous classification of a family. The procedure we have used is as follows. A first round of crosses is made which links the members of a family in an endless chain (i.e. $1 \times 2,2 \times 3,3 \times 4$ . . $19 \times 20,20 \times 21$ ). The information gained from this first round of pollinations generally leads to a provisional classification of a family, particularly if it contains only two classes. Thereafter, one or two further rounds of crosses are made. In each of these rounds, the crosses made are chosen on the basis of the information obtained from the previous rounds. Two or three rounds of crosses nearly always give a complete classification. Finally, half a dozen check pollinations are made whose predicted outcome is compared with the actual outcome. Because far fewer crosses are required with this procedure than with the more usual diallel method, the data matrices shown in figs. 3-4 and 6-9 are intentionally incomplete.

\section{RESUlts}

\section{(i) The gametophytic hypothesis}

The genetical test of the gametophytic hypothesis, to which we have submitted the data obtained from families $1^{\prime}, 1 \mathrm{~A}$ and $1 \mathrm{~B}$, depends on the fact that there is, as is well-known, a special set of pollination relationships between parents and their offspring in those species which possess a selfincompatibility system of the Nicotiana type and where the parents have one $S$-allele in common (see for example, Lewis, 1954). In these circumstances, the progeny fall into two cross-compatible classes, both of which are reciprocally compatible with the female parent, but only one of which is with the male parent, members of the other class having the same $S$-allele genotype as the latter, being reciprocally incompatible with it (fig. 1). Furthermore, though both reciprocal progenies contain two cross-compatible classes, only one of these occurs in both progenies (the common class III), the other, because it contains individuals which are incompatible with the male parent, being unique to each reciprocal (the non-common classes II and I). These relationships can be used to predict the outcome of pollinations made between parents and their offspring, on the one hand, and between reciprocal progenies, on the other. They thus provide a critical, genetical test of the gametophytic hypothesis. These relationships are shown in diagrammatic form in fig. 2.

We turn first to consider the results obtained from families $1 \mathrm{~A}$ and $1 \mathrm{~B}$ (figs. 3 and 4). We notice that in both of these families, the plants fall into two pollination classes. Though in both families the number of plants in one class is slightly greater than that in the other, the excess is in neither case significant. Lastly, in the few cases where pollinations were made reciprocally, all were either reciprocally half-compatible or reciprocally 
Parents of

families 1 and 1

Families 1 and $1^{\prime}$
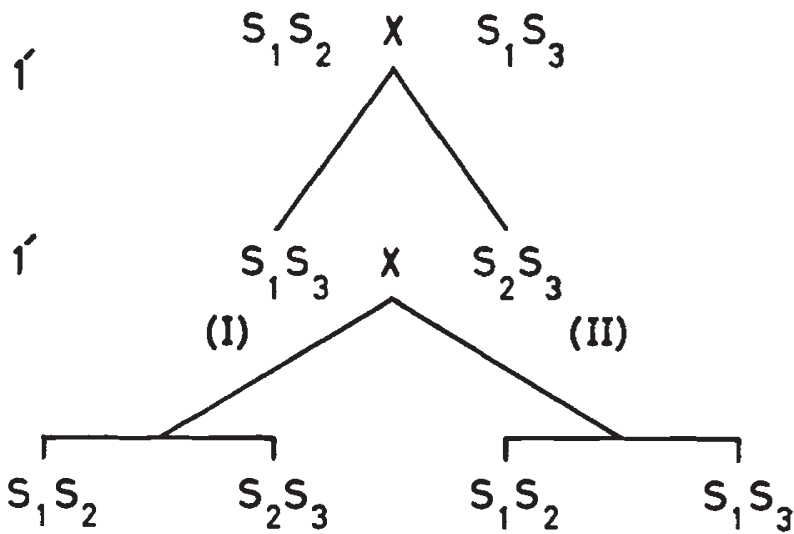

(III) (II) (III)

(I)

\section{Family 1A}

Family 1B

FIG. 1.-The inheritance of self-incompatibility. The parents of family 1 are assumed to have been of genotype $S_{1} S_{2}$ and $S_{1} S_{3}$. The Roman numerals (in brackets) indicate the genotypes of the three pollination classes that are expected on the one-locus, gametophytic hypothesis in this pedigree.

\begin{tabular}{|c|c|c|c|c|c|c|c|c|c|}
\hline Family & $\begin{array}{c}\text { Geno- } \\
\text { type }\end{array}$ & Group & $0^{7}$ & $\begin{array}{c}\mathrm{s}_{1} \mathrm{~s}_{3} \\
1\end{array}$ & $\begin{array}{c}\mathrm{S}_{2} \mathrm{~S}_{3} \\
\text { II }\end{array}$ & $\begin{array}{l}\mathrm{s}_{1} \mathrm{~s} \\
\text { III }\end{array}$ & $\begin{array}{c}\mathrm{S}_{2} \mathrm{~S}_{3} \\
\text { II }\end{array}$ & $\begin{array}{l}\mathrm{S}_{1} \mathrm{~S}_{2} \\
\mathrm{mII}\end{array}$ & $\mathrm{S}_{1} \mathrm{~S}_{3}$ \\
\hline \multirow{3}{*}{$i$} & & & & 1 & & 2 & & 3 & \\
\hline & $\mathrm{S}_{1} \mathrm{~S}_{3}$ & I & & - & + & + & + & + & - \\
\hline & $\mathrm{S}_{2} \mathrm{~S}_{3}$ & II & & + & - & + & - & + & + \\
\hline \multirow{3}{*}{$1 \mathrm{~A}$} & & & & 4 & & 5 & & 6 & \\
\hline & & III & & + & + & - & + & - & + \\
\hline & $\mathrm{S}_{2} \mathrm{~S}_{3}$ & II & & + & - & + & - & + & + \\
\hline \multirow{3}{*}{ 1B } & & Ix & & 7 & 1 & 8 & 1 & 9 & 1 \\
\hline & & $\mathbf{M A}$ & & 1 & & & $T$ & & + \\
\hline & $\mathrm{s}_{1} \mathrm{~s}_{3}$ & I & & - & + & + & + & + & - \\
\hline
\end{tabular}

F1G. 2.-The table shows in composite form the expected pollination relationships between individuals of reciprocal progenies (families $1 \mathrm{~A}$ and $1 \mathrm{~B}$ ) and between these and individuals of their parental generation (family $\mathrm{I}^{\prime}$ ). Half-compatible pollinations are shown as + and incompatible pollinations as - . The numbers $1-9$ in the top left-hand corners of the squares of the table identify the nine sets of crosses between the three families, each set containing two classes. 
incompatible. In all three of these respects, therefore, these families are in accord with expectation (fig. 2; squares 5 and 9 ).

The results obtained from crosses made between these two families are of much greater interest, however; these are shown in squares 6 and 8 of the composite fig. 5. We notice immediately that these results accord exactly with the predictions shown in the correspondingly numbered parts of fig. 2. We can, therefore, assign genotypes to each of the plants examined in families $1 \mathrm{~A}$ and $1 \mathrm{~B}$ according to the scheme shown in fig. 1. Thus members of the common, non-parental, class III of these families must be of genotype $S_{1} S_{2}$ (plants $1 \mathrm{~A} / 10$ and 1B/25); plant No. 30 of family 1A, since it is compatible with the members of the other two classes, must belong to the non-common, parental class II and is of genotype $S_{2} S_{3}$; similarly, plant No. 8 of family IB is of class I with genotype $S_{1} S_{3}$.

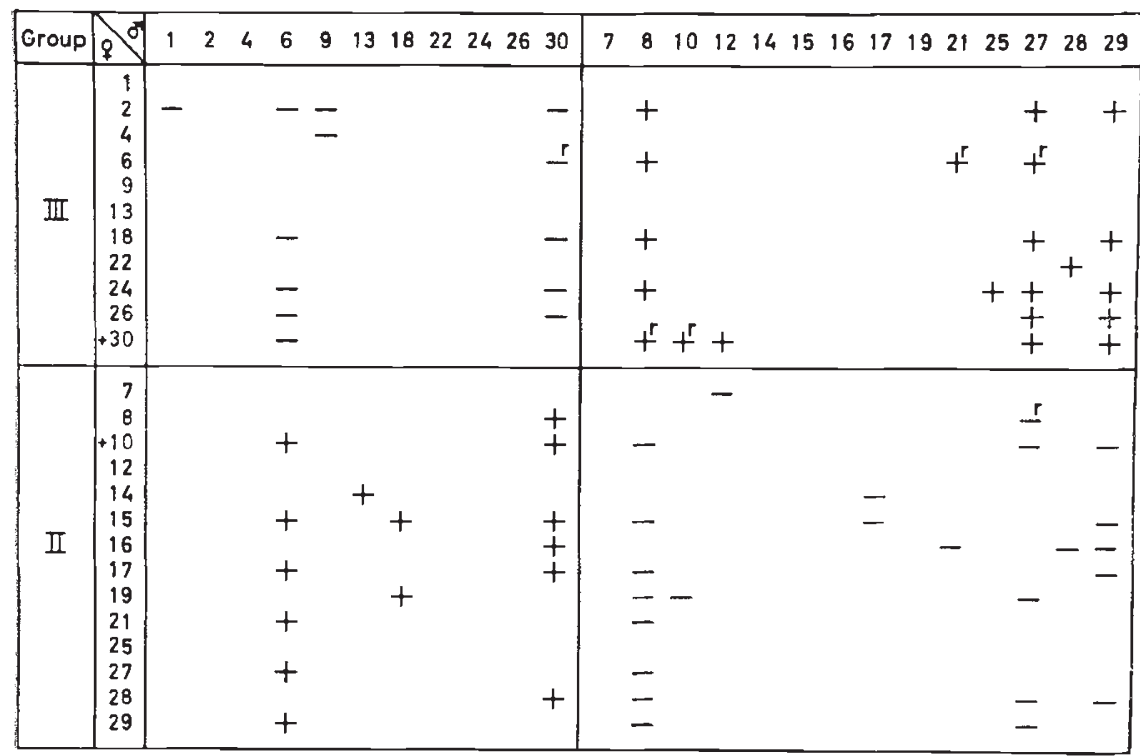

FIG. 3.-Family 1A. Entries in the top and left-hand margins of the table show plant numbers; a + indicates a plant used for inter-family crosses (see fig. 5). Pollinations made reciprocally are shown thus, $r$. Other details as for fig. 2. Summary of results, which are based on 72 pollinations:

$\begin{array}{lccc}\begin{array}{l}\text { Group } \\ \text { No. of plants }\end{array} & \text { II } & \text { III } & \text { Total } \\ & 14 & 11 & 25 \\ \chi_{(1)}^{2}=0.360, \quad P=0.70-0.50 & \end{array}$

We turn, lastly, to the results obtained from crosses between individuals from family $\mathrm{I}^{\prime}$ on the one hand and those from families $\mathrm{lA}$ and $\mathrm{BB}$ on the other hand. Now in a species with a strictly annual habit, such as $P$. rhoeas, it is not, of course, possible to backcross any of the offspring of a cross on to their parents directly (though storage of the pollen of the latter from one season to the next would permit one to carry out such backcrosses). The seed used to raise the plants of family $l^{\prime}$ however, came from the same packet as that used to raise those of family 1. In these circumstances, therefore, if the gametophytic hypothesis is true, we can predict that one plant of a 


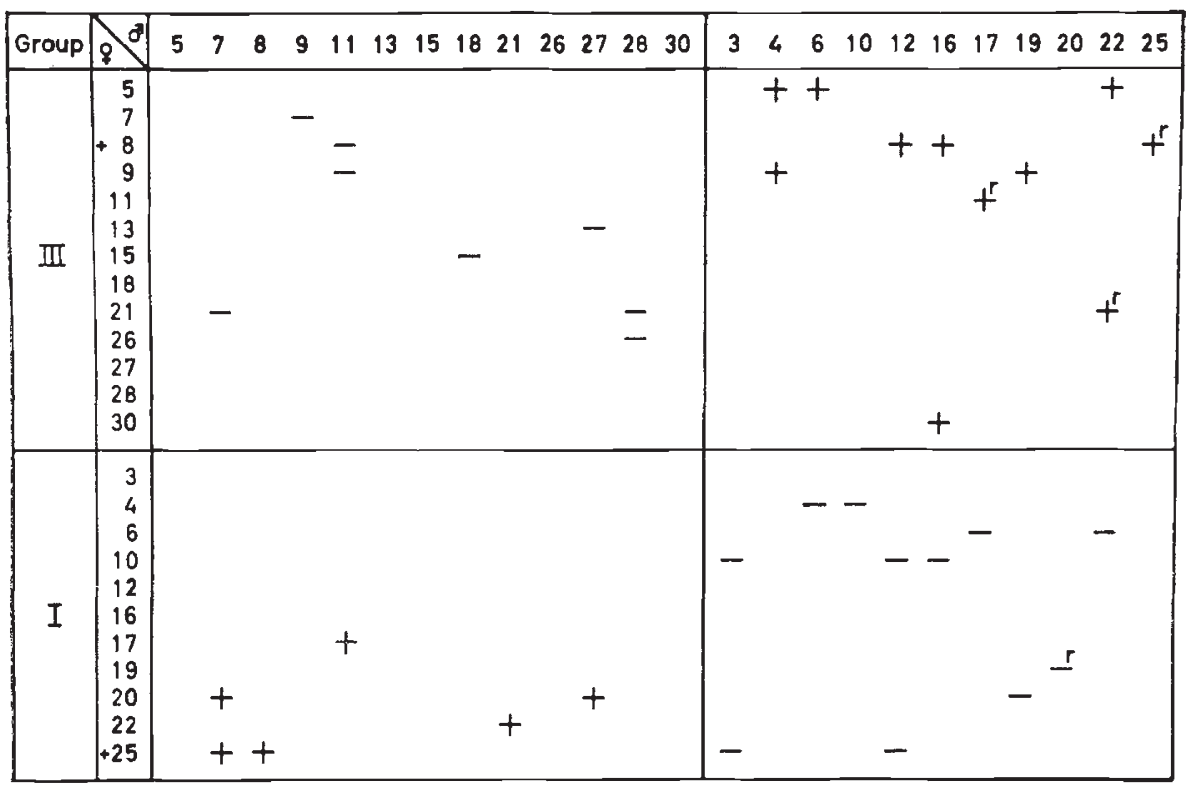

FIG. 4.-Family 1B. Details as for fig. 3. Summary of results, which are based on 36 pollinations:

$$
\begin{array}{lccc}
\text { Group } & \text { I } & \text { III } & \text { Total } \\
\text { No. of plants } & 11 & 13 & 24 \\
\chi_{(1)}^{2}=0.167, & P=0.70-0.50
\end{array}
$$

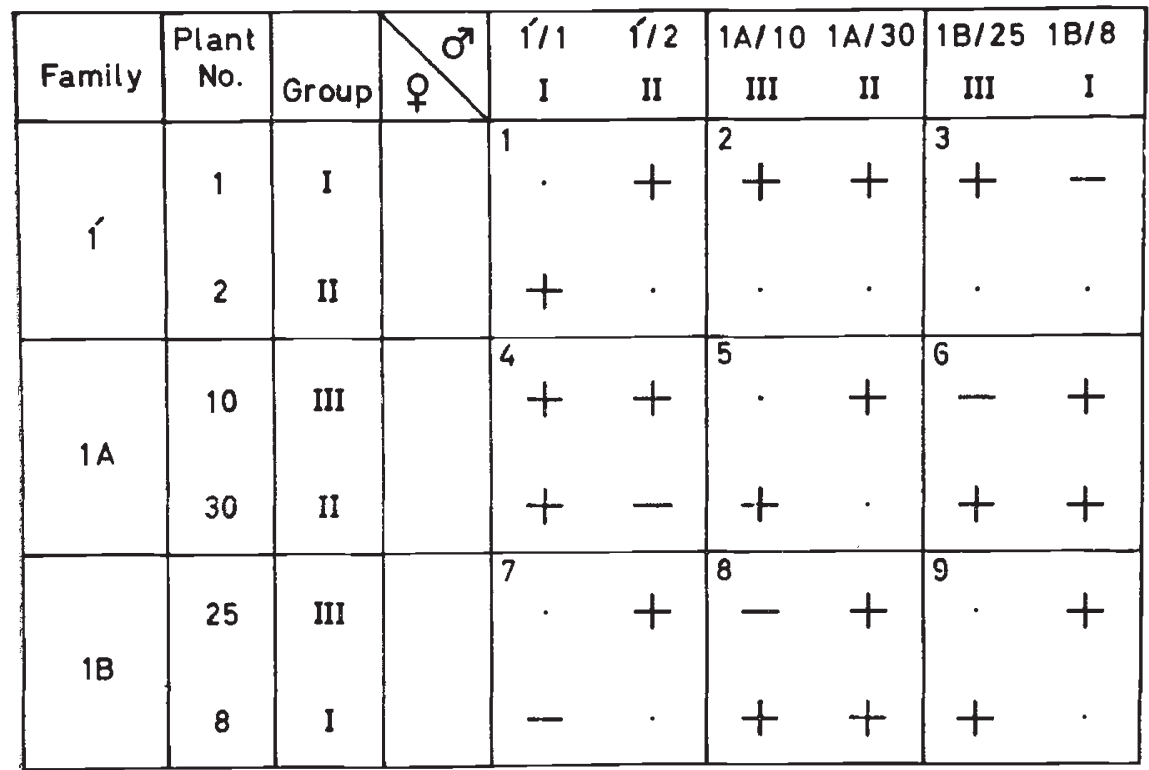

FIG. 5.-This composite table, which shows the results obtained from crosses made within and between reciprocal progenies (squares 6 and 8 ) and between these and individuals of their parental generation (squares 2, 3,4 and 7) is laid out in the same way as that shown in fig. 2 with which it should be compared. A dot indicates a cross not made. Other details as for fig. 2 . 
cross-compatible pair taken from family l' will be incompatible with a class I individual (e.g. 1B/8); that the other member of this pair will be incompatible with an individual of class II (e.g. 1A/30); and that all other pollinations between "parents" and offspring will be compatible. Though we were able to examine only 10 pollinations of a total of 16 possible between a pair of "parental " individuals from family $\mathrm{l}^{\prime}$ and a pair of "offspring " from each of families $1 \mathrm{~A}$ and $1 \mathrm{~B}$, the results obtained, shown in squares $2,3,5$ and 7 of fig. 5 confirm these predictions. Taken as a whole, therefore, these results leave no doubt that in $P$. rhoeas control of the pollen incompatibility phenotype is gametophytic rather than sporophytic.

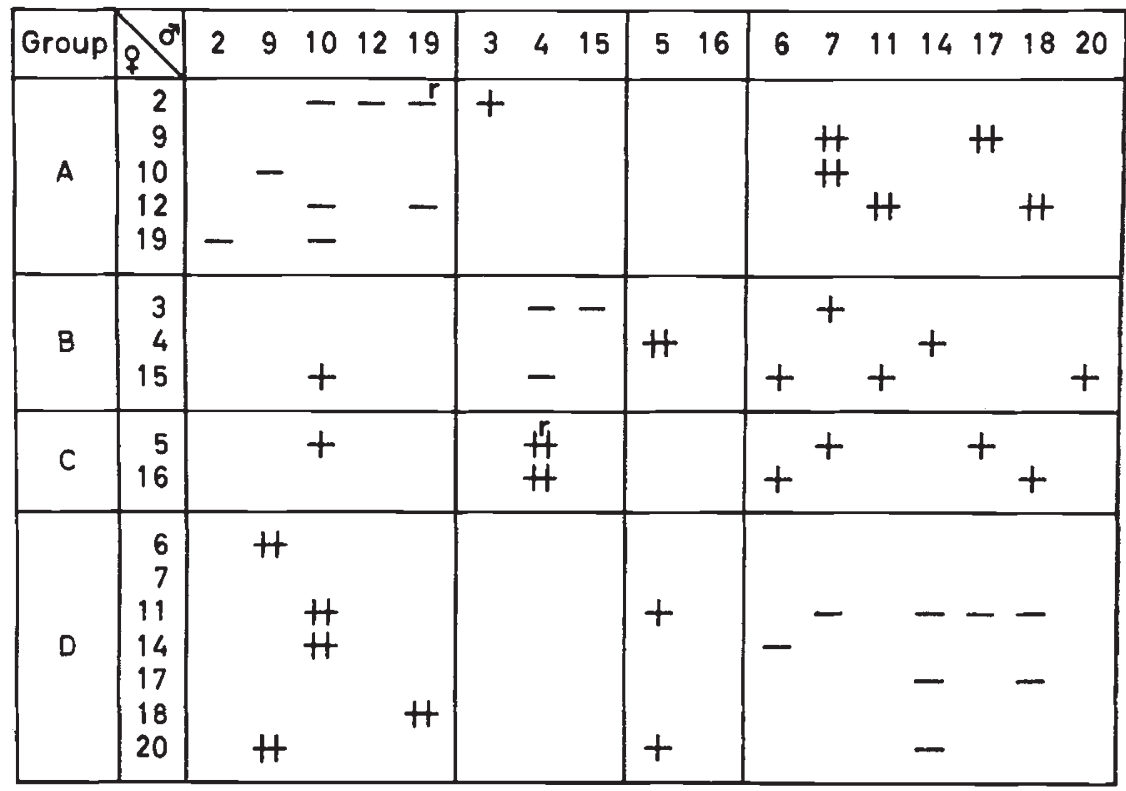

Frg. 6.-Family 73. Fully compatible pollinations are shown as \#. The plants in this and subsequent families have been classified into four arbitrary classes such that (i) those of Class $\mathrm{A}$ are fully compatible with those of class $\mathrm{D}$; (ii) those in class $\mathrm{B}$ are fully compatible with those of $\mathrm{C}$; (iii) and all other pollinations between plants of a different class are half-compatible. Other details as for fig. 3. Summary of results, which are based on 46 pollinations:

$\begin{array}{lccccc}\text { Group } & \text { A } & \text { B } & \text { G } & \text { D } & \text { Total } \\ \text { No. of plants } & 5 & 3 & 2 & 7 & 17 \\ & \chi_{(3)}^{2}=3.471, & P=0.50-0.30 & & \end{array}$

(ii) The one-locus hypothesis

The results obtained from the four non-inbred families are shown in figs. 6-9. In three of these families, 73,75 and 80 , the plants fall into four cross-compatible classes. Furthermore, in all three families the number of plants in each of the four classes is in good agreement with the expected 1: $1: 1: 1$ ratio, for none of the $\chi^{2}$ 's testing for goodness of fit in this respect are significant. 


\begin{tabular}{|c|c|c|c|c|c|c|c|c|c|c|c|c|}
\hline Group & $80^{\circ}$ & 2 & 3 & 5 & 6 & 1112 & 78 & 1016 & 1819 & & 1417 & $\begin{array}{lll}1 & 13 & 15\end{array}$ \\
\hline A & $\begin{array}{r}2 \\
3 \\
5 \\
6 \\
11 \\
12\end{array}$ & $\begin{array}{l}- \\
-\end{array}$ & - & $\begin{array}{l}- \\
-\end{array}$ & - & $-^{r}$ & & $+t$ & + & & & \\
\hline B & $\begin{array}{r}7 \\
8 \\
10 \\
16 \\
18 \\
19\end{array}$ & & + & + & + & + & $\overline{-}-$ & $\begin{array}{l}\text { r } \\
--.\end{array}$ & & & $\begin{array}{l}H \\
+\end{array}$ & + \\
\hline$C$ & $\begin{array}{r}4 \\
14 \\
17\end{array}$ & + & & & & + & $H$ & H & & - & $r$ & $t_{+}^{r}+$ \\
\hline D & $\begin{array}{r}1 \\
13 \\
15\end{array}$ & $\begin{array}{l}H \\
H\end{array}$ & & & $H$ & $H$ & & $+\underset{+}{+}$ & & & + & - \\
\hline
\end{tabular}

Frg. 7.-Family 75. Details as for fig. 6. Summary of results which are based on 53 pollinations:

$$
\begin{array}{lccccc}
\text { Group } & \text { A } & \text { B } & \text { C } & \text { D } & \text { Total } \\
\text { No. of plants } & 6 & 6 & 3 & 3 & 18 \\
& \chi_{(3)}^{2}=2.000, & P=0.70-0.50 & &
\end{array}
$$

\begin{tabular}{|c|c|c|c|c|c|c|c|c|c|c|c|c|c|c|c|c|c|}
\hline Group & 90 & 1 & 2 & 4 & 71 & 161 & 17 & 310 & 1219 & 5 & 6 & 8 & 9 & 11 & 13 & 141 & 15 \\
\hline A & \begin{tabular}{r|}
1 \\
2 \\
4 \\
7 \\
16 \\
17
\end{tabular} & & - & $\begin{array}{l}- \\
-\end{array}$ & $\begin{array}{l}- \\
- \\
-\end{array}$ & - & - & $\begin{array}{l}+ \\
+\frac{t^{r}}{t^{\prime}}+\end{array}$ & $\begin{array}{l}+ \\
+\begin{array}{l}+ \\
+\end{array}\end{array}$ & . & & & + & & & & + \\
\hline B & $\begin{array}{r}3 \\
10 \\
12 \\
19\end{array}$ & & & $\begin{array}{l}+ \\
+\end{array}$ & 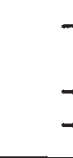 & $\begin{array}{l}+ \\
+ \\
+\end{array}$ & $\begin{array}{l}+ \\
+\end{array}$ & - & $\begin{array}{l}- \\
-\end{array}$ & & & & H & & & & \\
\hline C & $\begin{array}{r}5 \\
6 \\
8 \\
9 \\
11 \\
13 \\
14 \\
15\end{array}$ & & & $\begin{array}{l}+ \\
+ \\
+ \\
+\end{array}$ & + & + & $\begin{array}{l}+ \\
+ \\
+\end{array}$ & $H$ & $H$ & - & - & $\begin{array}{l}- \\
-\end{array}$ & - & - & - & . & \\
\hline
\end{tabular}

Frg. 8.-Family 76. Details as for fig. 6. Summary of results, which are based on 55 pollinations:

$$
\begin{array}{lccccc}
\text { Group } & \text { A } & \text { B } & \text { C } & \text { D } & \text { Total } \\
\text { No. of plants } & 6 & 4 & 8 & 0 & 18 \\
& \chi_{(8)}^{2}=7.778, \quad P=0 \cdot 10-0.05 & &
\end{array}
$$




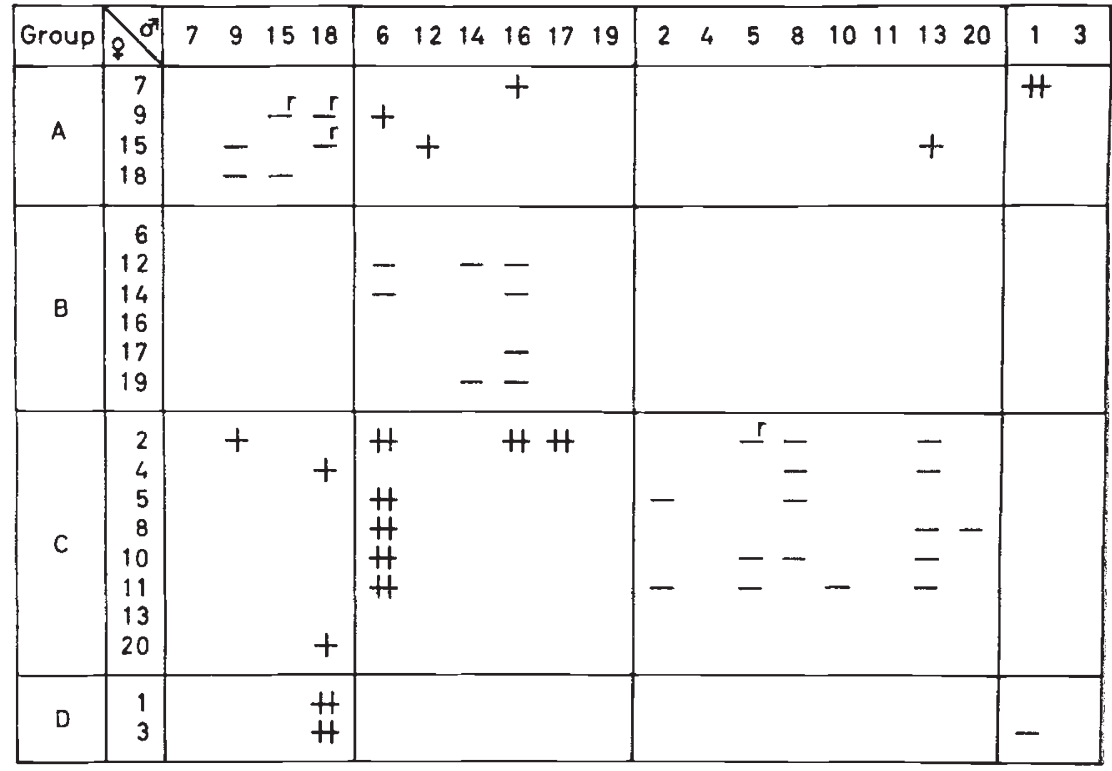

FIg. 9.-Family 80. Summary of results, which are based on 54 pollinations:

$\begin{array}{lccccc}\text { Group } & \mathrm{A} & \mathrm{B} & \mathrm{C} & \mathrm{D} & \text { Total } \\ \text { No. of plants } & 4 & 6 & 8 & 2 & 20 \\ & \chi_{(3)}^{2}=4.000, \quad \mathrm{P}=0.30-0.20 & & \end{array}$

In family 76 (fig. 8), on the other hand, only three classes of plants were found. At first sight, this is an unexpected outcome. Inspection of the pattern of pollinations obtained in this family, however, leaves little doubt that it is an incomplete four-class family, one class being absent. Indeed, though the $\chi^{2}$ testing for agreement with the expected $1: 1: 1: 1$ ratio is large, it is not, in fact, quite significant.

The obvious implication of this interpretation is that had more plants been raised in family 76 , one or more individuals would have turned up in the vacant class. Now in planning this experiment some thought was, of course, given to the question of family size in this respect. The calculation necessary for this purpose is an example of the classical occupancy problem (Feller, 1968; p. 102). Thus in general, if $\boldsymbol{P}_{m}$ is the probability that there: are $m$ missing classes,

$$
P_{m}=\left(\frac{n}{m}\right) \sum_{v=1}^{n-m}(-1)^{v}\left(\frac{n-m}{v}\right)\left(1-\frac{m+v}{n}\right)^{N}
$$

where $n$ is the number of equally represented classes in the population, $\mathcal{N}$ is the sample size, and $v$ is a dummy variable. In present circumstances, we wish, by choosing an appropriate value of $\mathcal{N}$, to make $P_{0}$, the probability of no missing classes, as large as possible. It can be shown that when, as in our case, $n=4$

$$
P_{0}=1-4\left(\frac{3}{4}\right)^{N}+6\left(\frac{1}{2}\right)-4\left(\frac{1}{4}\right)^{N}
$$


from which the following values of $P_{0}$ can be found:

$\begin{array}{rrl}\mathcal{N}=15 & P_{0}=0.9464 & \\ 16 & 0.9600 & \\ 17 & 0.9700 \text { (family 73) } \\ 18 & 0.9776 \text { (families 75 and 76) } \\ 19 & 0.9832 & \\ 20 & 0.9872 & \text { (family } 80) \\ 21 & 0.9904 & \end{array}$

Now in planning this experiment we were aware, from the calculations shown above, that 21 plants would be required in each family to give a 99 per cent chance of obtaining a complete family. Due, however, to the usual minor difficulties that are encountered with attempts to raise plants out of season, we lost a few more plants in each of these families than we had anticipated. In consequence, the actual probabilities of complete families are a little lower than intended. Nevertheless, none are less than 97 per cent, so that the probability of an incomplete family, $1-P_{0}$, even in the smallest family (family $73, \mathcal{N}=17$ ), is only 3 per cent. Furthermore, taking these results as a whole, the probability that, having raised four families of the indicated size, one or more of the $4 \times 4=16$ class-family combinations is absent is

$$
1-(0.9700)(0.9776)^{2}(0.9872)=0.0848,
$$

which, though as expected, is somewhat larger than $1-P_{0}$ for an individual family, is still rather small. For these reasons, it is difficult to avoid the conclusion that one of the assumptions underlying these calculations, namely, that the classes are equally represented in the population from which these families are samples, may not hold; that is, the individuals of some classes may enjoy a greater representation than others because of differential viability (of the gametophyte or sporophyte) or because of the linkage of the $S$-locus to other loci whose ratios are disturbed.This is clearly a matter which needs to be borne in mind when planning future experiments and, indeed, merits investigation in its own right.

Be this as it may, there is no doubt that the results that we have obtained from these four non-inbred families are most simply interpreted on the onelocus hypothesis. Thus, on this hypothesis we expect to obtain families of full-sibs whose members fall into four incompatibility classes whenever we cross two individuals which have no $S$-alleles in common. On the alternative multi-locus hypothesis, on the other hand, generally complete families contain more-often very many more-than four classes. For example, families of full-sibs in a species with a two-locus system of self-incompatibility, as in the grasses, can contain $6,8,12$ or 16 different classes, depending on the number of alleles that their parents have in common. However, it is also possible in these circumstances to obtain families which contain only four classes, as when for example, the parents are of genotype $S_{1} S_{2} Z_{1} Z_{1}$ and $S_{3} S_{3} Z_{2} Z_{3}$ as well as the more obvious pairing of $S_{1} S_{2} Z_{1} Z_{1}$ and $S_{1} S_{3} Z_{1} Z_{1}$ in which the individuals are identically homozygous with respect to the $Z$ locus. For this reason we cannot expect to be able invariably to discriminate between the one and the multilocus hypothesis and hence are unable definitely to refute the alternative, multilocus hypothesis on these data, as we were earlier able to do so in respect of the sporophytic hypothesis. 
On the other hand, since the parents of those four families were raised from seed taken at random from a large and flourishing natural population of the species, it is unlikely that all four pairings would have been of the special type shown above. The results we have obtained, therefore, are most reasonably explained on the assumption that $P$. rhoeas has a one-locus system of self-incompatibility.

\section{Discussion}

The results that have been obtained from this investigation of the selfincompatibility system of $P$. rhoeas raise a number of points for discussion of which three in particular are worth mention here. The first of these points concerns the kind of incompatibility system that we might expect to find in other species of the genus and of the family. Now on the rule that related species have the same kind of system, our finding that $P$. rhoeas has a one-locus, gametophytic system of the Nicotiana type suggests, of course, that other self-sterile members of the Papaveraceae are likely to have this kind of system too. However, so far as we are aware, though a number of other members of the family are known to be self-incompatible (Fryxell, 1957), $P$. rhoeas is the first to have been investigated in sufficient detail to establish the nature of its self-incompatibility system. It should, of course, be a relatively straightforward matter to verify this prediction and we have, accordingly, begun an investigation of some other self-sterile species with this aim in mind.

The second point worth making about these results concerns the site of inhibition of incompatible pollen. Generally, inhibition in species with a Nicotiana type of incompatibility system occurs in the style, although some exceptions to this rule are known. In P. rhoeas, on the other hand, incompatible pollen is inhibited either in, or, more probably, on the stigma. The question that arises in these circumstances is whether this is a familial characteristic, as it appears to be in the grasses, or whether, alternatively, stigmatic inhibition is peculiar to the genus Papaver because the flowers of all members of this genus are without a style.

Now Sykes (1976), who has examined 13 self-incompatible species of the family, found that in Meconopsis horridula, inhibition is stigmatic even though, like other members of this genus, the flowers of this species possess a short style. Thus while more observations of this kind are clearly required before this question of the site of inhibition of incompatible pollen in the Papaveraceae can be settled one way or another, it looks as if stigmatic inhibition is likely to turn out to be a familial, rather than a generic characteristic. Just why this should apparently be the case in the poppies, or, for that matter, among the self-incompatible grasses, is, on the evidence currently available very far from clear.

The third and final point that we wish to make concerns the light which our results from $P$. rhoeas cast on the question of the evolution of selfincompatibility in the angiosperms. Now earlier, we mentioned that (i) Lundqvist et al. (1973) and Østerbye (1975) had shown that Ranunculus acris had an incompatibility system that is controlled by not less than three, probably independent, multi-allelic loci, and that (ii) Cronquist (1968) and Takhtajan (1969) regard the order Papaverales as having originated as an evolutionary side-branch from the order Ranunculales. It will be recalled 
that hitherto our chief interest in these facts has been confined to the possibility that $P$. rhoeas might also possess a multilocus system of selfincompatibility. Now that we know, however, that this surmise is almost certainly false, our interest in this relationship changes. Thus if this phylogenetic conjecture is correct, it is difficult to avoid the conclusion that the one-locus system that we find in $P$. rhoeas may have evolved from a multilocus system of a kind similar to that found by Lundqvist and his colleagues in $R$. acris.

Now the hypothesis that one-locus systems of self-incompatibility have evolved, in some groups at least, from multilocus systems is not, of course, a new idea; Lundqvist (1975) for example, has recently argued the case for this view at some length. Hitherto, however, the evidence for this hypothesis has been of a rather general and indirect kind. There are, in fact, just two pieces of such evidence, one from the monocotyledons and the other from the dicotyledons.

In the monocotyledons, all of the grasses which have been investigated in sufficient detail have turned out to possess a two-locus system of selfincompatibility (Hayman, 1956; Lundqvist, 1956, 1961, 1962, 1965; Murray, 1974). Tradescantia paludosa, on the other hand, contrary to expectation, turned out to have a one-locus system (Annerstedt and Lundqvist, 1967). Since both Cronquist (loc. cit.) and Takhtajan (loc. cit) place the orders to which the grasses and the tradescantias belong, the Poales and the Commelinales respectively, in the same sub-class, the Commelinidae, a case can be made that these groups are related, albeit rather distantly. However, their relationship is held to involve a common ancestor, rather than one where one order has evolved from the other. For this reason it is not possible on this evidence alone to be sure whether the one-locus system of the type found in the present-day Commelinaceae has been derived from the multilocus system found in the Gramineae or vice versa.

In the dicotyledons, Lundqvist's discovery that a member of what is generally regarded as one of the more " primitive" orders of the flowering plants, the Ranunculales, has a multilocus system naturally invites speculation that systems of this type might be the progenitors of the one-locus systems found in members of the more " advanced" orders of the class, such as the Fabales, the Myrtales and the Scrophulariales. Yet, while the relationship in this case appears to have a direction, it is even more distant than that between the monocotyledonous orders, the Poales and the Commelinales.

The discovery that $P$. rhoeas has a one-locus system clearly provides on the face of it at least, some welcome support to this hypothesis. Thus if Cronquist's and Takhtajan's beliefs are correct, we now have a third case in which the taxa concerned, the Papaverales and the Ranunculales are both closely and directly related. The discovery of a single-locus system in a member of the former and a multilocus system in a member of the latter order clearly constitutes, therefore, the best evidence to date in favour of the hypothesis that one-locus systems have evolved from multilocus systems of self-incompatibility.

Yet in one respect, this new evidence is at variance with the earlier evidence. Thus as Lundqvist (1975) has stressed, a characteristic of species that possess multilocus systems is their immunity to polyploidy in the sense that the efficiency of their self-incompatibility appears to be relatively unimpaired when their number of chromosomes is doubled. This appears to 
be generally true for the grasses and the buttercups, irrespective of whether the polyploidy in question is spontaneous and long established or has been experimentally induced (Lundqvist, loc. cit.). On the other hand, in species which possess one-locus gametophytic systems, the effect of polyploidy is to weaken the expression of self-incompatibility because of competitive interaction of the $S$-alleles in the diploid pollen (Lewis, 1954). The one known exception to this rule is found in Tradescantia paludosa and its relatives in which polyploidy appears to have no more effect than it does in the grasses. Indeed, this similarity of behaviour in respect of the response to polyploidy is, of course, an additional reason for supposing that the relationship between the tradescantias and the grasses is reasonably close.

If, therefore, the one-locus system of $P$. rhoeas has evolved from a multilocus system similar to that found in the present-day buttercups, we might expect that the former species (and, indeed, all self-incompatible poppies) would respond to polyploidy in the same way as the latter. Such evidence as there is on this point suggests that this is not the case. Thus while we have yet to examine the effects of induced polyploidy in $P$. rhoeas, it is surely no coincidence that in a family in which polyploidy has clearly been an important agency of evolution, all 13 of the self-incompatible species that have been examined by Sykes (1976) turned out to have chromosome numbers at the diploid level $(2 n=12$ or 14$)$. On this evidence therefore, it can be predicted that the effect of doubling-up the chromosome number of $P$. rhoeas will be to impair the efficiency of its self-incompatibility systema prediction which clearly can and, indeed, will be put to the test.

Of course, the fact that the grasses and the tradescantias are both immune to the effects of polyploidy may be purely fortuitous. Furthermore, if the multilocus system of $R$. acris is accepted as the progenitor of the one-locus systems of the Leguminosae, the Onagraceae and the Solanaceae, it is necessary to suppose that the immunity to polyploidy of the former must have been lost sometime during the course of evolution of the self-incompatibility systems of members of the latter. The difficulty with the present case in this respect is, of course, that the Papaverales are supposed to be closely related to the Ranunculales. If, therefore, pace Lundqvist, immunity to polyploidy is an integral property of multilocus systems, it is difficult to advance an argument which says that the incompatibility system of poppies has evolved from that of the buttercups without, at the same time, being able to show that poppies too are immune to the effects of polyploidy. Thus, in principle, a one-locus system can be derived from a multilocus system in only one or two generations; all that is required is that all loci except one become homozygous. The loss of immunity to polyploidy however, must involve a much more fundamental genetical reorganisation of the system such as could hardly be accomplished in a short time. It is for these reasons that the question of the effects of polyploidy on the self-incompatibility of $P$. rhoeas is important.

Acknowledgement.-We are indebted to Dr J. S. Gale for help with the classical occupancy problem.

\section{REFERENCES}

ANNERSTEDT, I., AND LUNDQVIST, A. 1967. Genetics of self-incompatibility in Tradescantia paludosa (Commelinaceae). Hereditas, 58, 13-30. 
ARAsu, N. T. 1968. Self-incompatibility in angiosperms; a review. Genetica, 39, 1-24. GRONQUist, A. 1968. The Evolution and Classification of Flowering Plants. Nelson, London. Feller, w. 1968. An Introduction to Probability Theory and its Applications, Vol. I. John Wiley, New York.

FRyXell, P. A. 1957. Mode of reproduction of higher plants. Bot. Rev., 23, 135-233.

HAYMAN, D. L. 1956. The genetical control of incompatibility in Phalaris coerulescens. Desf. Aust. 7. Biol. Sci., 9, 321-331.

LAWrence, M. J. 1975. The genetics of self-incompatibility in Papaver rhoeas. Proc. $R$. Soc. Lond. B., 188, 275-285.

LEWIS, D. 1954. Comparative incompatibility in angiosperms and fungi. Advan. Genet., $6,235-285$.

LUNQVIsT, A. 1956. Self-incompatibility in rye. I. Genetic control in the diploid. Hereditas, 42, 293-348.

LuNDQVist, A. 1961. Self-incompatibility in Festuca pratensis. Huds. Hereditas, 47, 542-562. LUNDQVIST, A. 1962. Self-incompatibility in diploid Hordeum bulbosum L. Hereditas, 48, 138-152.

LundQvist, A. 1965. Self-incompatibility in Dactylis aschersoniana Graebn. Hereditas, 54, 70-87.

LundQvist, A. 1975. Complex self-incompatibility systems in angiosperms. Proc. R. Soc. Lond. B., 188, 235-245.

LUNDQVist, A., øSTERBYe, U., LARSEN, K., AND LINDE-LAURSEN, I. 1973. Complex selfincompatibility systems in Ranunculus acris L. and Beta vulgaris L. Hereditas, 74, 161-168. MARTiN, F. W. 1959. Staining and observing pollen tubes in the style by means of fluorescence. Stain Technology, 34, 125-128.

mUrRay, B. G. 1974. Breeding systems and floral biology in the genus Briza. Heredity, 33, 285-292.

øSterbye, U. 1975. Self incompatibility in Ranunculus acris. Hereditas, 80, 91-113.

PANDEY, K. K. 1957. Genetics of self-incompatibility in Physalis ixocarpa Brot.-a new system. Amer. J. Bot., 44, 879-887.

PANDEY, K. K. 1962. Genetics of incompatibility behaviour in the Mexican Solanum species S. pinnatisectum. Zeit. fur Ver., 93, 378-388.

sYkes, s. R. 1976. A survey of the breeding system with special reference to self-incompatibility in the Papaveraceae. M.Sc thesis, University of Birmingham, England.

Takhtajan, A. 1969. Flowering Plants; Origin and Dispersal. Oliver and Boyd, Edinburgh. 